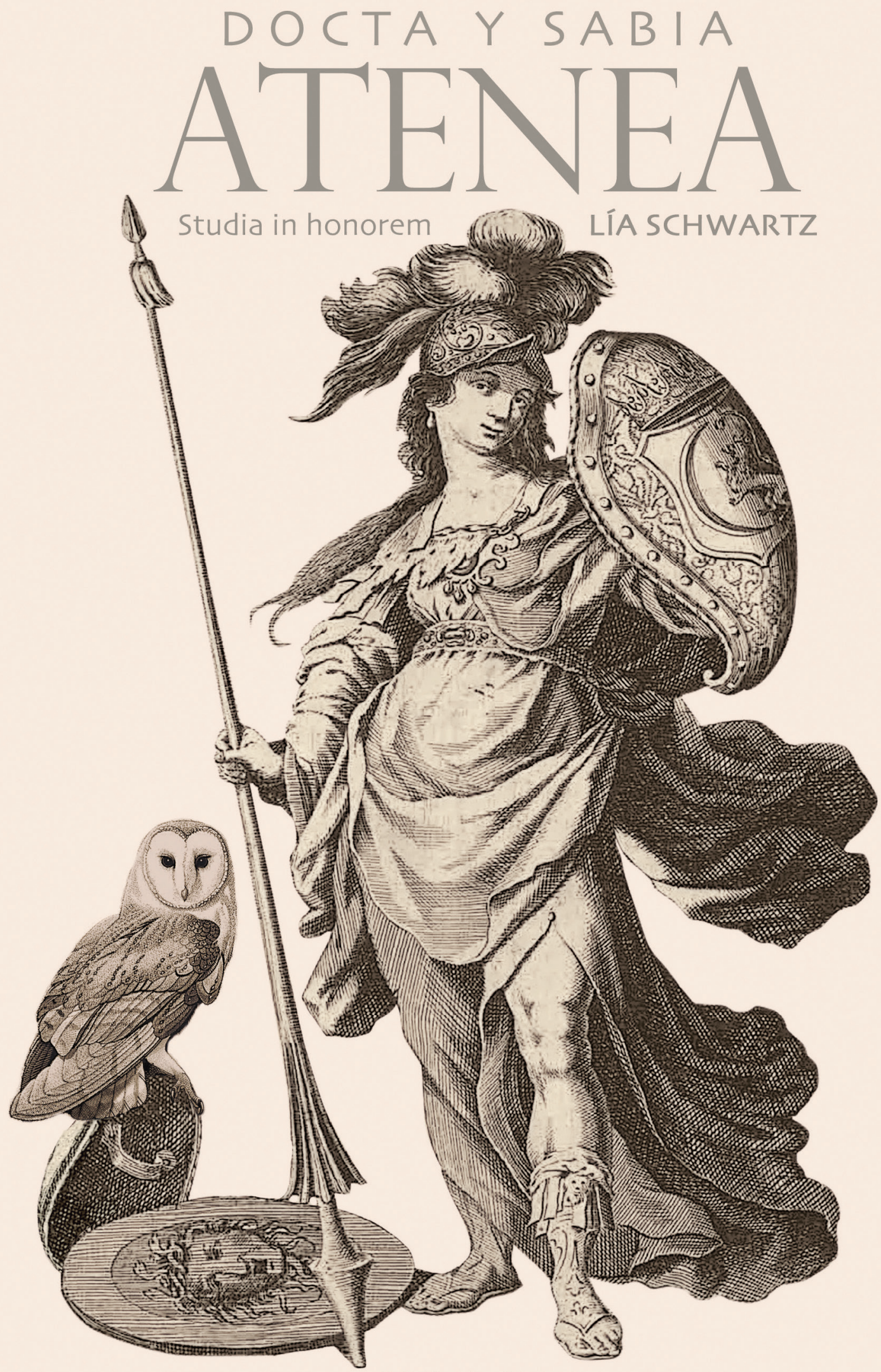

Edición al cuidado de:

SAGRARIO LÓPEZ POZA, NIEVES PENA SUEIRO, MARIANO DE LA CAMPA, ISABEL PÉREZ CUENCA, SUSAN BYRNE Y ALMUDENA VIDORRETA 



\section{DOCTA Y SABIA ATENEA Studia in honorem Lía Schwartz}

Edición al cuidado de:

Sagrario López Poza, Nieves Pena Sueiro, Mariano de la Campa, Isabel Pérez Cuenca, Susan Byrne y Almudena Vidorreta

A Coruña, 2019 

Profesora Lía Schwartz

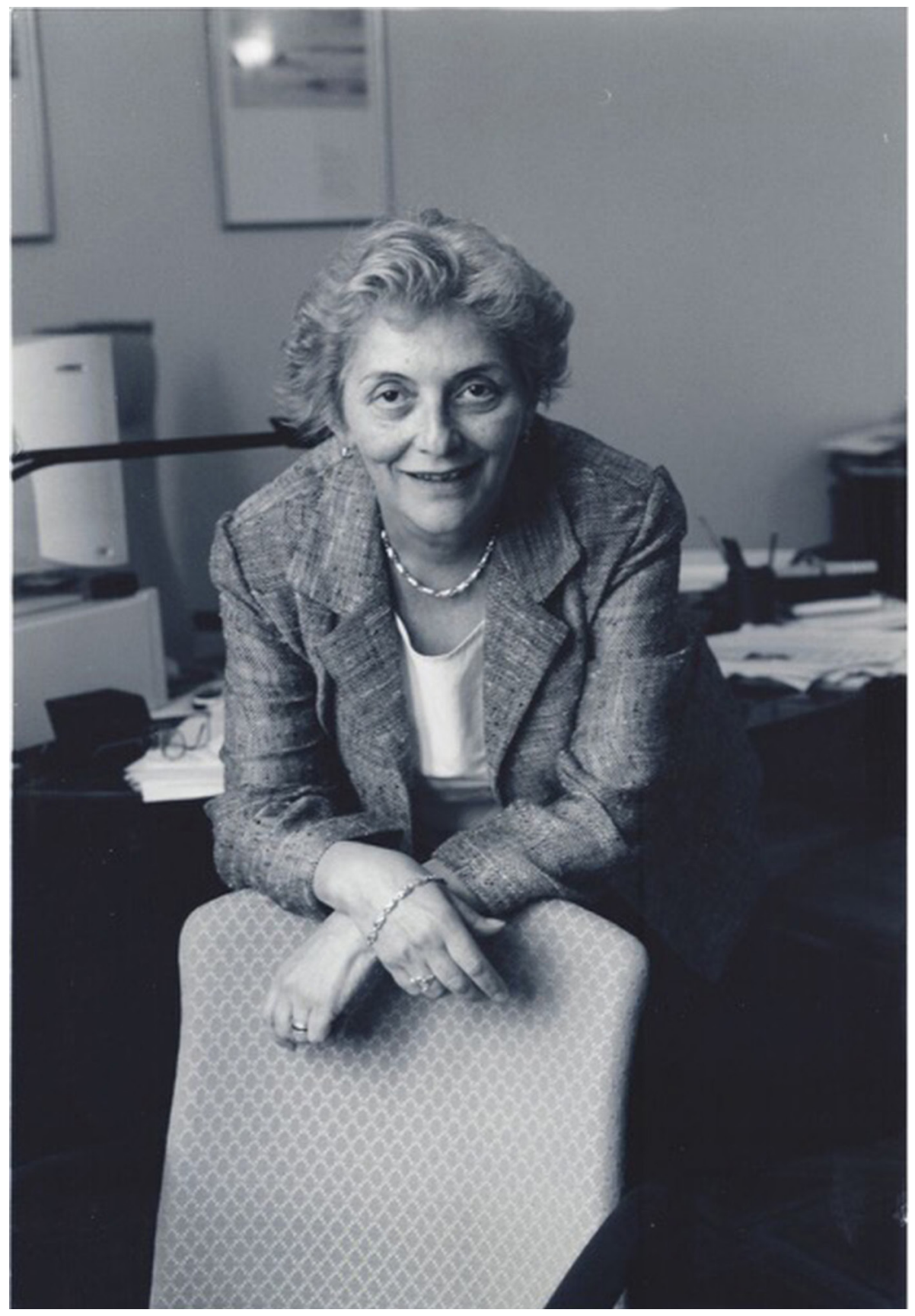


Sagrario López Poza, Nieves Pena Sueiro, Mariano de la Campa, Isabel Pérez Cuenca, Susan Byrne, Almudena Vidorreta (editores)

Docta y sabia Atenea. Studia in honorem Lia Schwartz

N. ${ }^{\circ}$ de páginas: 832

$17 \mathrm{x} 24 \mathrm{~cm}$.

Índice: pp. 7-10

ISBN: 9788497497046

Depósito Legal: C 53-2019

CDU: $821.134 .2(082.2) *$ SCHWARTZ

IBIC: DS | 2ADS | DQ

Editan:

Universidade da Coruña, Servizo de Publicacións

Instituto Universitario "La Corte en Europa" (IULCE), Universidad Autónoma de Madrid

Hispanic Seminary of Medieval Studies (HSMS), New York

Queen Sofía Spanish Institute, New York

Seminario Interdisciplinar para el estudio de la Literatura Áurea Española (SIELAE), Grupo Hispania, Universidade da Coruña

(C) Los autores

(C) De esta edición:

Servizo de Publicacións, Universidade da Coruña

Colección: Homenaxes n. ${ }^{\circ} 14$

Diseño de la cubierta: Paula Lupiáñez (Cirugía Gráfica. Madrid)

Interior: Juan de la Fuente

Impreso en Lugami Artes Gráficas, Betanzos (España)

Printed in Spain 


\section{ÍNDICE}

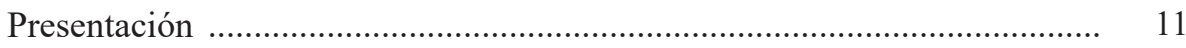

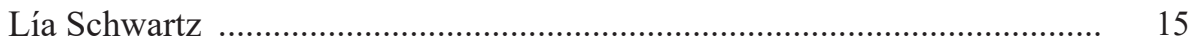

Bibliografía de Lía Schwartz ................................................................. 19

\section{Estudios en homenaje a la profesora Lía Schwartz}

Antonio Azaustre

Notas sobre la filiación en la tradición manuscrita de El alguacil endemoniado

Mercedes Blanco

Para una definición del gongorismo. El caso de Nueva España

69

JAVIER BLASCO

«Salta Pan, Venus baila, Bacho entona»: el campo léxico de la música como vehículo del erotismo en la poesía de los Siglos de Oro

SUSAN BYRNE

La armonía neoplatónica en "A Francisco de Salinas» de fray Luis de León

Mariano de La CAMPa

Poemas de Quevedo en impresos del siglo XVII: Los Romances varios .....

Manuel Ángel Candelas

La poesía española en los manuscritos de la Biblioteca Nazionale di Napoli: noticias y textos

ANTONIO CARREÑo

Lope de Vega: «Rompa ya el silencio el dolor en mí»

Donald CRUickshank

Don Toribio Cuadradillos, «avestruz del amor», and El lindo don Diego (with a note on Quevedo) 
María D'Agostino

Un juego de espejos deformantes. La «representación» del conde de Lemos entre Argensola y Cervantes

TREVOR J. DADSON

«Yo no puedo salir del trabajo de parecer a los portugueses castellano y a los castellanos portugués»: Diego de Silva y Mendoza y la poesía hispanoportuguesa de principios del siglo XVII

Ottavio Di Camillo

Of Roasted Eggs and Other Issues in the Celestina

Aurora EGIDO

Retórica y poética de los afectos en el soneto XIV de Garcilaso 265

Santiago Fernández Mosquera

El vicio de la virtud en Los trabajos de Persiles y Sigismunda 283

Flavia Gherardi \& Pedro Cátedra

El Discorso in difesa della poesia de Gian Ambrogio Biffi en el ámbito de la poética italiana y española

AdRIÁN M. IZqUiERDO

Paráfrasis y experimentación poética en el Anacreón castellano de Quevedo

HILAIRE KALLENDORF

Splitting Hairs or Finding Threads: The Labyrinth as Metaphor for Moral Dilemma in the Comedia

José ENRIQUE LAPLANA

La erudición en el Para todos de Juan Pérez de Montalbán

Begoña LóPEZ Bueno

El Ramillete de las Musas Castellanas (Bibliothèque Mazarine, ms. 4047): un canon literario español en el siglo XVII francés. Primera parte

SAGRARIo LóPez PozA

«Amoris vulnus idem sanat, qui fecit». Notas sobre la fortuna de un topos clásico

ISABEL LOZANO RENIEBLAS

El mal latín del episodio de dos falsos cautivos del Persiles 
Alison Maginn

Rubén Darío's Final Chapter: Archer Milton Huntington and the Hispanic Society

Miguel Martínez

Góngora asiático. Notas sobre poesía filipina inédita del primer Barroco ....

José Martínez MiLlán

Isabel Clara Eugenia, ¿una infanta castellana?

Clayton McCarl

Hacia un modelo para el marcado semántico de los textos marítimos de la época colonial

\section{Juan Montero Delgado}

Un soneto desconocido de Pedro Espinosa a Francisco de Rioja en el ms. Span 56 de la Houghton Library (Universidad de Harvard) 561

Nuria Morgado

Pervivencia del Barroco en la poética de la modernidad: intuiciones y conceptos en el pensamiento literario de Antonio Machado

FRANCISCA MOYA DEL BAÑo

La presencia de Plauto en Quevedo

VALENTINA NIDER

El oro como botín en los poemas de Quevedo sobre Belisario (B-267 e

B-281) y el contexto literario hispano-italiano

ISABEL PÉREZ CUENCA

Francisco de Quevedo y Antonio Sancho Dávila y Toledo Colonna, III marqués de Velada

FERnANDo Plata

El sentido de «barranco» en La Perinola de Quevedo y en otros textos del Siglo de Oro 653

José María Pozuelo Yvancos

Interdiscursividad: cine y literatura en Javier Cercas 671

Augustin Redondo

El tema de la mujer caída de una torre abajo: tradiciones culturales (grecolatinas, bíblicas, folklóricas), creencias religiosas y creaciones cervantinas ... 
MANUEl Rivero RODRÍGUEZ

El conde duque de Olivares, mecenas de la Historia y creador de opinión ... 701

MARIE RoIG Miranda

Los Sueños de Quevedo o cierto tipo de novela 723

Melchora Romanos

Séneca en las Anotaciones de Pedro Díaz de Rivas a los poemas mayores de Góngora

JAVIER SAN JosÉ LeRA

La Política de Dios de Quevedo como comentario bíblico: Política, Biblia y Literatura

LuIs SÁNCHEZ LAÍlLA

Ignacio de Luzán y la musa bucólica

Almudena Vidorreta

Teresa de Jesús, precursora de Gabriela Mistral y Alfonsina Storni

JUAN DiEgo VILA

«con las ansias de la muerte»: El aparato prologal del Persiles como programa estético del estilo tardío cervantino 


\title{
«con las ansias de la muerte»: El aparato prologal del Persiles como programa estético del estilo tardío cervantino
}

\author{
JUAN Diego ViLA \\ Universidad de Buenos Aires
}

Para la querida Lía, maestra ejemplar, entrañable amiga.

\begin{abstract}
$-\mathrm{I}-$
Volver al Persiles, en el cuarto centenario de su publicación póstuma, dista mucho de ser una opción crítica carente de sobresaltos. Puesto que, tal como lo clarificó Pelorson, los cuatro siglos transcurridos, en términos de hipótesis de lectura, interpretaciones, saberes de época o indagaciones filológicas, no han coadyuvado — a pesar de lo profuso de esta produccióna la conformación de un saber basal sobre la más enigmática de todas las novelas cervantinas ${ }^{1}$. Pues cada abordaje, incluso los más recientes,

1 Jean-Marc Pelorson (2003) sostiene que «Las síntesis de muchos manuales de historia de la literatura y de muchos artículos más o menos perentorios y dotados al final de una bibliografía apabullante pueden dar al lector profano, que intenta orientarse por el Persiles, la impresión de que existe un enorme 'saber' ya constituido. Las notas proliferantes de la edición de Carlos Romero refuerzan esta impresión, poniendo a disposición del lector todo o casi todo lo que se dijo acerca de tal o cual detalle del texto» (p.8). Mas agrega, a continuación, con evidente tono concesivo, que «el sentido crítico es lo que más importa, sobre todo tratándose de una novela víctima de una larga tradición de prejuicios, tópicos y lecturas esquemáticas» (p.8).
\end{abstract}


parecen verse compelidos a replantearse, desde cero, todas las directrices básicas de las hipótesis que organizan la narración por las dificultades que suponen, para cada lector, avalar y partir de los asertos téticos de la órbita crítica previa.

Fenómeno equívoco que ordenó las contradicciones de los primeros estudiosos o que polarizó, en épocas más recientes, pareceres diametralmente contrapuestos. Gregorio Mayáns y Siscar fue el primero en sostener, en 1737, que se estaba en presencia de la «obra maestra del autor», pero no resulta comprensible que le atribuyese un comprobable éxito editorial análogo al del Quijote - en términos de reediciones y traducciones- y que, a renglón seguido, pautara el disfavor popular ${ }^{2}$. Una suerte de best seller sin el apoyo del público. En las antípodas, Menéndez y Pelayo no vaciló en predicar que las aventuras de Periandro y Auristela eran el ejemplo palmario de la débil senilidad de don $\mathrm{Miguel}^{3}$ mientras que, en tiempos más recientes, Juan Bautista Avalle-Arce suscribió paroxísticos encomios en el prólogo a su edición ${ }^{4}$ según los cuales todo resultaría una perfecta y acabada cifra del arte de novelar.

El paneo por pareceres igualmente terminantes y en algún punto dogmáticos podría extenderse al infinito pero su recorrido se revela innecesario por cuanto, para el cometido de esta lectura, la gran mayoría de ellos expresa un mismo foco de incomodidad lectora. Pues el Persiles hace

2 «En suma, esta obra es de mayor invención, artificio y de estilo más sublime que la de Don Quijote de la Mancha. Pero no ha tenido igual aceptación, porque la invención de la Historia de Don Quijote es más popular y contiene personas más graciosas y, como son menos en número, el lector retiene mejor la memoria de las costumbres, hechos y caracteres de cada una. Fuera de eso, el estilo es más natural y tanto más descansado cuanto menos sublime» (Mayans y Siscar, 1972: 180-181).

3 Reténgase, no obstante, que los pareceres de don Marcelino fueron diversos. En su juvenil Historia de los heterodoxos españoles su valoración fue estrictamente negativa: «Y, sin embargo, cuando en su vejez hizo un libro de aventuras, especie de novela bizantina, imitación de Heliodoro, tejida de casos maravillosos, no dudó, sin duda por débil senilidad, en acudir a los prodigios algo pueriles de la magia». En tanto, que, tiempo después, sostuvo en "Cultura literaria de Miguel de Cervantes y elaboración del Quijote» que «Mucho más de personal hay en la obra de la vejez de Cervantes, en el Persiles, cuyo valor estético no ha sido rectamente apreciado aún, y que contiene en su segunda mitad, algunas de las mejores páginas que escribió su autor» (1941: 323-356).

4 «Así y todo, ha quedado un torso que debe provocar admiración en todo lector. Porque el Persiles es la verdadera novela de un novelista, en el sentido con que ni soñó Palacio Valdés. El Persiles es una novela, es una idea de la novela, y es la suma de todos los puntos de vista posibles en su tiempo sobre la novela» (Avalle-Arce, 1987: 27). 
colapsar múltiples anhelos totalizadores que persiguen la predicación de un estilo cervantino que aglutine sus ficciones en prosa.

En efecto, quienes han apostado por una matriz evolutiva - sea cual fuere el objeto de análisis elegido como variable determinante: ya la representación de la realidad y el privilegio y exploración de ciertos géneros, ya los dispositivos enunciativos en términos de mayor o menor control de la ficción gestada, ya el tratamiento de alguna temática recurrente- no logran sortear con holgura el precedente insoslayable de los logros expresivos alcanzados por las dos partes del Quijote pues a la luz del consenso dominante sobre su valía se satura cualquier expectativa teórica de indagación de un progreso. ¿Cómo ponderar el Persiles después del Quijote?

$\mathrm{Y}$, desde otro ángulo, tampoco hubo mayores logros cuando el dispositivo implementado procuró una armonización equilibrada de diversidades evidentes pues la simetría o una disposición especular en la secuenciación de las novelas no bastan para explicar por qué una gran parte de la fábula de la Historia Septentrional se repliega más dócil sobre la coordenada imaginaria idealista propia de la Galatea. Con el Persiles, al fin de cuentas, se derrumba la ilusio de una clave totalitaria como respuesta a la pregunta por el arte cervantino.

Es por ello, entonces, que nos resulta imperiosa la postulación de un estilo tardío cervantino que permita conformar un ciclo de senectute en la producción autorial. Puesto que - como lo demostrara magistralmente Juan Manuel Rozas (1990) en el caso de Lope, en senda que, en nuestros días, ha vuelto a transitar Oleza (2003 y 2004) — las particularidades de un conjunto de obras entre las cuales el Persiles es faro inequívoco se ven sobredeterminadas por las preocupaciones teórico-conceptuales sobre la propia producción, por las reevaluaciones del propio emplazamiento simbólico en un sistema literario regido por dispositivos de mecenazgo (Wright, 2001; Vélez-Sainz, 2006) y por una insoslayable meditación de la propia finitud.

\section{-II-}

Las así definidas «obras testamentarias» suelen descansar en la hipótesis de que los grandes creadores anuncian, de un modo desviado y con estrategias de corte alegórico, la propia finitud en sus producciones. De lo cual se seguiría que estas obras perfilan, en la temporalidad de la ficción 
engarzada con la del sujeto, un estilo de vejez que permitiría pensar, de un modo diverso, la producción terminal de muchos grandes maestros ${ }^{5}$.

Forzoso es precisar, no obstante, que no todos los creadores tienen un estilo tardío ni que todas las obras últimas son, por definición, tardías. Habida cuenta de que lo medular, para el primer supuesto, es el reconocimiento de aquellas trayectorias individuales en las cuales lo final no supone coronación armónica de una trayectoria creativa precedente y que, en lo que respecta a la evidencia de que todo artista tiene siempre una última creación, no es la simple fortuna biológica de cada cual lo que dirime un problema estético sino, antes bien, la intelección profunda de la finitud ${ }^{6}$. Pues lo tardío florece, siempre, en un escenario catastrófico signado por la contradicción del adagio de Hipócrates: «Ars longa, vita brevis».

Datos éstos, además, a los cuales es necesario acompasarle el recordatorio de que su interés minoritario en las agendas críticas pende, en forma forzosa, del privilegio conferido a los constructos estéticos supra individuales ${ }^{7}$. Y si bien es bien evidente — como lo demuestra María

5 «Finalmente, llego a la última gran problemática, que, por motivos personales y obvios, es el tema que voy a tratar: el último período, o tardío, de la vida, la decadencia del cuerpo, el deterioro de la salud u otros factores que, incluso en el caso de una persona joven, dejan entrever la posibilidad de un final prematuro. Me centraré en grandes artistas y en el hecho de que, cuando se acercaba el final de sus vidas, su obra y pensamiento adquieran un nuevo lenguaje, que llamaré estilo tardío`» (Said, 2009: 28)

6 Michael Wood señala las múltiples perspectivas en que hay que analizar la problemática temporal y la finitud del creador: «Conviene detenerse a analizar los diversos matices de la palabra 'tarde' y sus derivados, que pueden hacer referencia desde las citas a las que no acudimos a una parte del día, o a una lengua que se encuentra en la última fase de su existencia. No obstante, en la mayoría de las ocasiones 'tarde' solo significa 'demasiado tarde', más tarde de lo que se había pactado, impuntualidad. Sin embargo, los frutos tardíos o el otoño tardío son del todo puntuales, no se rigen por otro reloj o calendario. Lo tardío no hace referencia a una única relación con el tiempo, pero siempre deja una estela de tiempo a su paso. Es una forma de recordar el tiempo, ya sea pasado, vivido o perdido» (13-14).

7 Las historias literarias al uso suelen privilegiar el emplazamiento de los autores en marcos estéticos que exceden y trascienden la singularidad de la figura de todo creador. De allí que, caprichosamente, se potencien las catalogaciones opinables de determinadas figuras en la sucesión de escuelas estéticas y que, ligado a ello, se tienda a neutralizar, sin mayores miramientos, las diferencias al interior de una misma producción. Los frescos mayestáticos del gran arte literario — pero también pictórico o musical — tienden a infravalorar las producciones contracorrientes y los posicionamientos alternos frente a dominantes estéticas de un momento dado. Cervantes, por caso, sería inmejorable ejemplo: ¿es renacentista, es barroco, debemos habilitar el período menos frecuentado del manierismo? ¿Todo se explica por una única coordenada? 
Zerari-Penin (2014) - que en los últimos decenios se constata una floración crítica y museológica enfocada en la producción terminal de muchos maestros de la pintura ${ }^{8}$, la configuración de este objeto de análisis en el dominio literario carece, a pesar del estatuto señero de ciertos abordajes, de análoga trascendencia9 .

En el dominio cervantino, por caso, sólo se constata el reciente volumen de Giuseppe Grilli (2016) —De senectute. Cervantes último- y dos artículos que ligan la hipótesis de un estilo tardío con el Persiles: uno de Jean Canavaggio (2014) y otro de Mario Ortiz Robles (2016). Aunque, en los tres casos, los presupuestos teóricos son diversos del enfoque que aquí desearía presentar.

En el de Ortiz Robles se propone un análisis del relato de la propia historia que Periandro asume en el libro II puesto que permite focalizar, con precisión, las opinables ligazones entre experiencia y discurso. Y se vale, para ello, del rastreo de ciertos topos literarios - la fortuna, la ventura, el cielo - para insistir en la noción de discontinuidad, existencial y elocutiva, como marca de lo tardío ${ }^{10}$.

8 Las exposiciones así nucleadas, en las cuales múltiples críticos, estudiosos y curadores se consagraron, son: «L'oeuvre ultime: de Cézanne à Dubuffet» (Fundación Maeght, 1989), «Zurbarán. La obra final: 1650-1664» (Bellas Artes de Bilbao, 2000-2001), «Le dernier Titien et la sensualité de la peinture» (Academia de Venecia, 2008), «La sainte Anne, l'ultime chef-d'oeuvre de Léonard de Vinci» (Louvre, 2012), «El último Rafael» (El Prado, 2013), «Raphaël, les dernières années» (Louvre, 2013).

9 El trabajo de Zerari-Penin — que oficia de pórtico al conjunto de contribuciones nucleadas - recuperaba que, en el ámbito de las letras, un primer asedio sistémico se encontraría en un trabajo de Rachel Bespaloff, quien en los años 50 potenciaba asertos de Hermann Broch para configurar su «Introduction a L'Iliade». Broch planteaba la noción de estilo de vejez y la especialista francesa lo potenciaba para pautar un estilo mitificante.

10 «The dilatory quality of Periandro's storytelling I have been describing in this reading is in keeping with the dissonant form of the novel, which, fissured and rent by figural and narrative interruptions, becomes scarred by the history of its present. As Periandro puts it after he saves the life of a suicide on his ship: 'Y ¿qué mayor mal puede venir a un hombre que la muerte? Y, siendo esto así, no es locura el dilatarla: con la vida se enmiendan y mejoran las malas suertes y, con la muerte desesperada, no sólo no se acaban y se mejoran, pero se empeoran y comienzan de nuevo' (366). Periandro's story makes visible the formal patterns that structure the novel as a whole, patterns whose purpose seems to be at once to dilatar death and to enmendar life's fortunes in the process of capturing life's evanescence aesthetically. Cervantes's late style in the Persiles makes visible a fierce resistance to death that also constitutes, for the artist, an uncompromising skepticism regarding the redemptive possibilities of aesthetic works» (Ortiz Robles, 2016: 425). 
La opción de Canavaggio, preocupado por auscultar la palabra final del autor del Quijote, enfila por otras vías, aunque, también, insiste en una focalización debatible. Ya que, en su caso, no postula un estilo de vejez sino, antes bien, la emergencia de cierta tópica conclusiva y funeraria en la «Dedicatoria»y en el «Prólogo» ${ }^{11}$. Asedio temático que lo conduce al recupero obligado de una muy fina interpretación de la argentina Teresa Herráiz de Tresca (1988) ${ }^{12}$.

La tesis de Grilli, para nada desdeñable, es que la filiación crítica y editorial de la Primera Parte del Quijote a su Segunda Parte supone el sacrificio tácito del Persiles en múltiples perspectivas de análisis por cuanto, según sostiene, la secuela de 1615 se encontraría mucho más próxima al texto póstumo - en principios constructivos estéticos- que a la novela consagratoria de 1605 .

Mi hipótesis, por el contrario, y a ello dedicaré estas páginas, es que el díptico paratextual estudiado por Canavaggio concentra un programa de lectura tardío del Persiles porque los dispositivos que allí se ponen en juego o se llegan a sugerir tibiamente ofician de clave de acceso privilegiada para la postrera novela cervantina.

\section{-III-}

Un primer detalle a retener es el de las estrategias sustitutivas de lo anecdótico ficcional, propio de todo volumen que se presenta, por guiños biográficos que historian, en el territorio alterno, una biografía fracturada signada por refracciones ínfimas y silencios circundantes. Pues, a diferencia de todas las escrituras de prefación cervantinas, aquí nada se dice de la

11 «Si, en effet, nous embrassons dédicace et prologue dans une même visée, cette expérience est celle d'une vie qui s'achève et d'une mort non seulement attendue dans la dignité, mais aussi évoquée avec une élégance et un humour qui forcent l'admiration. À ce titre, ces pages dictées sur un lit d'agonie se distinguent de toutes celles qui les ont précédées» (Canavaggio, 2014).

12 «'Lo que se dirá' queda por siempre fuera del texto y de nuestro conocimiento : no se nos dice a qué alude Cervantes ni menos cómo piensa a cuatro días de su muerte, y con tan clara conciencia de ella, escuchar 'lo que se dirá de mi suceso' ; ni dónde sitúa el tiempo que 'vendrá, quizá', en que pueda 'anudar el roto hilo' y decir 'lo que aquí me falta y lo que sé convenía' : o en qué consiste esa certeza aludida y señalada, no descripta o designada» (Herráiz de Tresca, 1988: 58). 
obra que se preludia ${ }^{13}$. A punto tal que lo vital astillado parece recuperado para oficiar de caja de resonancia de las directrices de la ficción.

Bien visto está que, leídas en conjunto, la apertura de la dedicatoria a través de la inclusión de la famosa glosa «Puesto ya el pie en el estribo», remite a los orígenes líricos de toda la trayectoria artística de Cervantes y que el prólogo se cierra con la escena de la marcha a caballo que han compartido dos desconocidos que se han amigado en el trayecto, inequívoca cifra del texto que le valió fama mundial. Trazo fantasmático que importa recuperar porque el Persiles, en sí mismo, es también una fábula sobre un viaje que culmina y se clarifica en el origen ${ }^{14}$, territorio metafórico que, en la ficción, nos lega, en sordina, el eco de lo no dicho ni representado en la dedicatoria y el prólogo.

Por eso mismo uno de los primeros señalamientos es que lo tardío se acrisola en el recupero de una coordenada mitificante puesto que en lo mítico se reuniría la potencialidad de decir el mundo, un universo vital y ficcional, que se despliega, con ojos entrecerrados, para decir lo que fue, lo que podría haber sido y lo que faltó. Mitificación que en la prefación se vuelve legible en todas las pistas biográficas: el mecenazgo fallido — pues el interlocutor de la dedicatoria sólo llegará a leerla cuando Cervantes ya esté muerto- - la ciudad de Esquivias — con la cual se historia su vida afectiva - o el motivo del presunto linaje de los vinos — presumible causa de su enfermedad pero también, con seguridad, risueño desvío de la angustia fundante de todo sujeto que se sabe vigilado, desde antes de nacer, en una

13 La «Aprobación» de José de Valdivieso insiste en que el libro «de cuantos nos dejó escritos, ninguno es más ingenioso, más culto ni más entretenido; en fin, cisne de su buena vejez, casi entre los aprietos de la muerte cantó este parto de su venerando ingenio». Hay valoración, pero ningún indicio descriptivo del contenido. En la «Dedicatoria» a don Pedro Fernández de Castro lo que Cervantes focaliza, a nivel argumental, es el excedente de futuras producciones anunciadas, pero nada de la obra presentada: «Todavía me quedan en el alma ciertas reliquias y asomos de Las semanas del jardín y del Famoso Bernardo. $\mathrm{Si}$, a dicha, por buena ventura mía (que ya no sería ventura, sino milagro), me diese el cielo vida, las verá y, con ellas, fin de La Galatea, de quien sé está aficionado Vuesa Excelencia». Y es sabido, por último, que no hay mayores precisiones en el «Prólogo» (Cervantes Saavedra, 1997: 103 y 108-109).

14 Seráfido será el encargado de precisar, en los capítulos conclusivos de la novela, que la matriz clarificadora de la peregrinación toda depende del origen escamoteado, punto de partida en el cual la reina Eustoquia asume el riesgo afectivo y político de alentar al hijo segundo a huir en peregrinación junto a Auristela, heredera de un reino próximo, prometida, casualmente, al hijo mayor y heredero. 
cultura signada por la limpieza de sangre y la excecración del distinto-. Mitificación críptica que también orienta la fábula de quienes están llamados a ser reyes ${ }^{15}$ en el utópico reino de Tule, gesta que, sugestivamente, Cervantes ha ambientado en tiempos de Carlos V cuando, no casualmente, sólo es un niño de 11 años y la vida, ante todo, puede representársele como un proyecto infinito de múltiples alternativas y no, claramente, como un milagro que, en su fuero íntimo, intuye que no sucederá.

Toda mitificación, por economía expresiva, impacta claramente en un lenguaje preñado de resonancias por lo cual, a las claras, un corolario práctico insoslayable es que todo lo narrado parece sucumbir a una suerte de abstracción por medio de la cual el sentido y los mensajes tienden a privilegiar la dimensión sintagmática estructural. Fenómeno que Theodor Adorno puntualizó cuando - a propósito del Beethoven tardío - insistió en la prevalencia de leyes formales en el proceso compositivo que se revelan como un sendero de negatividad de todo lo propio precedente ${ }^{16}$. Pues el artista tardío apuesta a la incomodidad.

Y ese gesto de evaluación inmisericorde de lo propio - en la vida y en el arte- también es perfectamente legible. Pues la escena del viaje parece cincelada para desmontar todo espejismo existencial y el sendero de las vanidades de todo artista. Cervantes es, primero, confundido con alguien que marcha a la Corte a medrar. En tanto que, a renglón seguido y cuando su identidad se devela, se siente íntimamente forzado a admitir el equívoco que la gloria literaria supondría. No es el regocijo de las Musas y su éxito, si es tal, sólo puede entenderse como el logro de un escritor festivo que

15 «Los trabajos de Persiles y Sigismunda son una historia de amor, mezclada de incidentes variados - raptos, secuestros, hechizos, solicitaciones imperativas - que todos vienen a tener una sola causa: la violencia del poder» (Molho, 2005: 579).

16 En el ensayo señalado Said comenta un aserto de Adorno sobre esta temática en su «Late Style in Beethoven» publicado en Essays on Music: «Así, la gran fuerza del estilo tardío de Beethoven es negativa, o, más bien, es negatividad: donde cabría esperar serenidad y madurez, hallamos un reto peliagudo, complejo y pertinaz, tal vez incluso inhumano. 'La madurez de las obras tardías - afirma Adorno - no se asemeja a la de la fruta. No son ... redondas, sino que parecen arrugadas, incluso agrietadas. Carecen de dulzura y, ásperas y espinosas, no se rinden a la mera degustación'. Las obras tardías de Beethoven son irreconciliables y marginadas por una síntesis superior: no encajan en ningún sistema y no se pueden reconciliar ni resolver, puesto que su irresolución y fragmentariedad no sintetizada son constitutivas, ni son ornamentales ni simbólicas ni nada más. De hecho, las composiciones tardías de Beethoven tratan sobre la 'totalidad perdida' y, por lo tanto, son catastróficas» (35). 
encuentra en ese lector «pardal» el estándar de insuficiencia consagratoria que ha merecido lo propio. A lo cual se suma, como golpe de gracia, el que sólo un compañero de tal catadura — amigable, sí, pero muy tonto-, pueda pensar en la cura necesaria para su enfermedad. El futuro, bien lo sabe, es ese horizonte abierto al más allá y no, por caso, la fantasía de una cura.

El develado de la identidad es, asimismo, un principio constructivo del Persiles. El lector es invitado, desde la titulación misma, a sospechar que Persiles y Sigismunda sean, probablemente, nombres velados de los protagonistas cuyas identidades, casi seguramente, diferirán en mucho de la pretextada hermandad que se anuncia una y otra vez. Juego semiótico que, merced al despliegue de las identidades alternas, pospone el peso y la gravedad de asumir quien se es ${ }^{17}$.

Estrategia magistral que cala aún más hondo cuando, intrigados, los lectores comienzan a reparar que la disposición a experimentar vidas no nominadas por el verdadero nombre propio, el estatuto real y la coordenada existencial originaria que nunca termina de revelarse, parece ser, también, la hoja de ruta del autor al componer puesto que múltiples horizontes de expectativas que los lectores vieron descartar en fábulas previas parecen alzarse, indómitos, en esta ficción final.

Es claro, el Persiles apuesta por la abstracción estructural de las ficciones cervantinas ya conocidas porque, en definitiva, parece acuciado por la necesidad de explorar, a título fantasmático o cadavérico, las opciones desechadas años atrás. Pues la última novela parece organizarse, por momentos, por los extraviados senderos de los futuros imaginarios que jamás fructificaron porque el autor optó, en su momento, por otras resoluciones ficcionales.

El caso más emblemático es el del enamorado portugués en cuyo relato reverberan los parámetros argumentales de La española inglesa para, en inaudito giro, espectacularizarse una de entre muchas vidas alternas

17 La tópica de la identidad velada, como protocolo regulador de la trama, es tributo claro de Cervantes al magisterio de Heliodoro. Con todo, no obstante, se impone considerar que esta adhesión imaginaria en pleno siglo XVII español entraña, sustantivamente, severas implicancias ideológicas. Puesto que lo que se le ofrece al colectivo de lectores coetáneos es, fingimientos mediante, la hipótesis de una existencia velando la propia identidad por finalidades estratégicas. Identidad que, culturalmente, se ve férreamente regulada y codificada según los distintos estamentos y hábitats. 
que Isabela y Recaredo no merecieron ${ }^{18}$. Pero también podría auscultarse semejante latir proscripto en la secuencia de Feliciana de la voz ante la trama de La señora Cornelia ${ }^{19}$ ya que, con mayor o menor alcance, el Persiles parece diseñado para los lectores que Cervantes intuye como su público fiel y buen conocedor de sus ficciones.

$\mathrm{Y}$ anejo a este recupero estructural de lo conocido - por momentos muy enmascarado - puede pensarse el detalle de que el estilo tardío en Cervantes se ve transido por un tono de exilio - bella imagen que debemos a $\mathrm{Said}^{20}$ - Pues este incesante juego enunciativo de flujo y reflujo, que fuerza la coexistencia de tiempos, espacios, fábulas y coordenadas imaginarias le transmiten al acto de narrar el efecto insoslayable de la urgencia. De donde, en consecuencia, la evidencia lectora de cómo toda la sucesión de historias anudadas a la marcha de los protagonistas tiende a estar imbuida de urgencia enunciativa en desmedro de los protocolos de naturalización de estas criaturas a los que el público estaba acostumbrado con Cervantes ${ }^{21}$.

18 Es bien evidente que tanto La española inglesa como el Persiles incluyen el anuncio del paso obligado por el convento para un matrimonio místico en un caso y para una boda seglar en el otro. Mas en sendas ocasiones el territorio de unión sacralizada fracasa. Isabela será detenida en la puerta frontera al monasterio por un rescatado y sorpresivo Recaredo mientras que, en la historia del portugués enamorado, esto se invierte. Quizás, entre otros motivos, porque la prometida lo esperaba en el interior del claustro desde el día previo. Se da, a las claras, un entrelazamiento quiasmático. Y esta desigual cohesión entre preparativos y consecuencias es la que determina que en la última novela cervantina se termine explorando, de un modo casi contrafactico, las consecuencias negadas por la providencial reunión de los enamorados en el primer texto que ofició de inspiración.

19 Los motivos del hijo abandonado por la parturienta y los caballeros amigos dispuestos a auxiliarla son, en esta ocasión, los puntos en torno a los cuales se edifica la reescritura de la célebre secuencia que termina con los peregrinos en Guadalupe en el libro III.

20 «Por lo tanto, lo tardío es una suerte de exilio autoimpuesto que llega después y sobrevive a lo que es en general aceptable. De ahí la evaluación que Adorno hace del Beethoven tardío y su propia lección para su lector. La catástrofe que representa el estilo tardío para Adorno es que, en el caso de Beethoven, la música es episódica, fragmentaria, resulta dividida por las ausencias y silencios que no se pueden llenar mediante un plan general y específico, ni tampoco se pueden pasar por alto y restarles importancia diciendo 'Pobre Beethoven, estaba sordo, se aproximaba a la muerte, son pequeños fallos a los que no debemos dar importancia'» (Said, 2009: 39).

21 Avalle-Arce argumenta a este respecto que lo que privilegia Cervantes es la idea de la peregrinación en desmedro de la naturalización de las criaturas ficcionales. Ya que hay un anhelo de significar la universalización de la experiencia humana y, para ello, se privilegia la 'cadena del ser' de cuño alegórico. Por lo cual no asombra que señale: «Porque 
Pues, así como la marcha de Cervantes con el estudiante en el prólogo adquiere el estatuto de anécdota o mero fresco vital - momento que se recupera por su significancia en detrimento de ópticas y relatos más extensos- el juego enunciativo del Persiles impone el reconocimiento de la despreocupación autorial por el aparente fragmentarismo resultante en la visión de una totalidad. Pues la resistencia del estilo tardío, en cierto primitivismo constitutivo, se delata, culpable, en el triunfo indolente de lo episódico desentendido de la continuidad del todo. Por eso, claro está, muchas obras tardías suelen percibirse como inacabadas.

Porque la urgencia que domina la enunciación, nostálgica, melancólica o saturnina, de tiempos en fuga y tiempos que ya no son tales porque no habrá un después - lo tardío, en definitiva, es punto final que aniquila la trascendencia-, permite revelar cómo toda escritura tardía está inhabitada por la contradicción. Lo triste se mezcla con la humorada - como cuando Cervantes se despide de los amigos deseándolos ver pronto en el más allá (Vélez-Sainz, 2016) - , el desencanto, con el placer y lo trágico con la diversión.

Punto, este último, que no debería soslayarse desde ningún ángulo en un estudio del Persiles como obra tardía puesto que - tal como Edward Said lo enfatizaba - el entretenimiento, en los dominios del arte, se revela siempre como un tipo particular de resistencia. Porque el entretenimiento, al igual que el placer y la intimidad, no requiere por parte del productor o consumidor artístico, una reconciliación con el statu quo o los regímenes dominantes.

Y el Persiles, ya lo clarificó con toda holgura Augustin Redondo (2004), es también un libro de entretenimiento. Criterio categorial que en tiempos de Cervantes impugnaba de cuajo a todos los tratadistas al uso y en boga, pero también, disposición escritural — centrada en la hexis barthesiana del 'placer del texto'- que se complace en la fragua de dos héroes de lo maravilloso que combinan los mitemas de Perseo y Aquiles para el protagonista masculino o las directrices de Astrea y Pudicitia para Auristela. No faltan

universalizar implica también abstraer, ya la universalización y la abstracción son dos aspectos del mismo quehacer intelectual. La intención universalizadora del autor tiene, como consecuencia y contrapartida, la abstracción. Y por ello, los principales personajes del Persiles son todos unidimensionales y acartonados. No son cuerpos opacos de carne y hueso sino transparentes símbolos de validez universal: Persiles y Sigismunda son los perfectos amantes cristianos, Rosamunda es la lascivia, Clodio la maledicencia, etc» (1987: 27). 
- según el hispanista francés - remisiones múltiples a la mitografía sobre Venus ni, tampoco, en el caso del príncipe de Dinamarca, reformulaciones de tradiciones populares como la que presenta el romance del conde Arnaldos.

El entretenimiento, en este ángulo de lectura resistente propia de lo tardío, alienta un posicionamiento ideológico bien particular porque se revela medular - como lo expresaba el crítico palestino - para cuestionar todo sueño o anhelo de reconciliación. Ya que para los cultores del estilo tardío la pulsión reconciliadora deviene testimonio palmario de la imposibilidad de pensar la dificultad y la diferencia. Y el Persiles, en este sentido, se revela pletórico en polaridades que, desafiantes, cuestionan presupuestos lectores, siembran engaños en exégesis apresuradas y resisten, incólumes, ante el totalitarismo de una única interpretación final. Un maniqueísmo fallido se ofrece desde la evidente contraposición de la saga marítima septentrional con la peregrinación por tierra del Mediterráneo $\mathrm{o}^{22} \mathrm{y}$, con resultados igualmente indirimibles, concluyen los ejes isotópicos — como el de la polaridad barbarie/civilización - si se desea afinar la perspectiva.

Cervantes, en su obra tardía, confirma su maestría en la representación de marginalidades, periferias olvidadas y detalles minorizados que impugnan, gustosos, cualquier síntesis, porque — según Stathis Gourgouris (2005) lo tardío es el posicionamiento y la estrategia de escritura por medio de la cual se desafían los puntos débiles del presente, los paliativos del pasado y las imágenes del futuro que nos asedian. Dato que importa recuperar para pensar - en la línea de los bien fundados asedios de Isabel Lozano- por qué, en términos estéticos, el Persiles pudo ser objeto en su tiempo de un impacto atenuado al tiempo que, para la historia canónica de la evolución de la novela en el siglo XVIII, debería considerárselo precedente señero. Pues el Persiles fue un reloj que atrasaba y adelantaba a la vez ${ }^{23}$.

22 Uno de los engaños evidentes del texto es el de la expedita contraposición entre peripecias septentrionales — propias de la barbarie nórdica- y aventuras meridionales. Pues si bien el contrapunto entre confines de oscuridad y claridad - con todos los valores simbólicos morales asociados a cada núcleo- es un trazo que se deja leer, no es menos cierto, con todo, que la peregrinación por tierras conocidas revela tasas de violencia y crueldad notoriamente semejantes a las que se habían bosquejado en los libros I y II. Y es un dato también a retener — como lo sugiere con claridad Jean-Marc Pelorson (2003) que el epíteto de 'bárbaro' acompañará, siempre, al personaje del español Antonio.

23 Alban K. Forcione (1969) trabaja la imagen de un tiempo roto, fragmentado, en una de las consagradas producciones tardías del ciclo de senectute lopesco, La Dorotea. 
Y en este diálogo con la propia cultura, con las convenciones artísticas y con la propia finitud es particularmente inquietante que la última novela cervantina se revele, enigmática e incansable, como palimpsesto infinito del problema de la enunciación y el silencio (Lamanna, 2007). Porque esa misma tensión - rastreable tanto en los convencionalismos adoptados para una fábula multicultural ${ }^{24}$ como en las estratégicas elisiones de información entre personajes y para con el lector - es prueba insoslayable de que lo callado no equivale a la nada y que su misterio se yergue, una y otra vez, para acrisolar la intelección del lector para con la ficción y el propio mundo. Para articular, silencioso, una mediación no dicha, para susurrar, proscripto, lo que no se ha dicho y quizás convendría callar.

El Persiles tardío, al fin de cuentas, está todo por leerse. Y en su sombrío resplandor fracturado, que a nuestros tiempos se ofrece, late no sólo la angustia humana por la necesaria renuncia a una totalidad huidiza sino también el desafío, más actual que nunca, de deponer toda trágica nostalgia por la unidad perdida en beneficio de una reconciliación con la diversidad.

\section{BiBLIOGRAFÍA}

Avalle-Arce, Juan Bautista, «Introducción biográfica y crítica», en Cervantes, Miguel de, Los trabajos de Persiles y Sigismunda, Madrid, Clásicos Castalia, 1987.

Canavaggio, Jean, «De la dédicace au prologue du Persiles: le fin mot de Cervantès», E-Spania, 18, Juin, 2014.

24 Uno de los aspectos que potencia la lectura Pelorson (2003) es que el Persiles se ofrece, novedosa en tiempos de cerrazón ideológica, como una fábula decididamente multicultural. Y que esto se vuelve legible en la dedicación puesta en los procesos de verosimilización de la interacción de personajes de tan diversas naciones. Cervantes rechaza - por obvios motivos estético-comunicacionales para con sus lectores- la alternativa de un poliglotismo explícito pues nadie habría podido, en su tiempo, dominar tanta variedad de lenguas como las nacionalidades involucradas lo exigirían. Pero igualmente enfatiza que rechaza la opción antagónica de que todos se expresen en español - la lengua del público - sin hacer constar cómo eso sería posible. La alternativa que califica como superadora y dominante en el Persiles es la de un poliglotismo implícito. Pues al dejarse constancia en el texto que la comunicación es compleja, que son necesarios mediadores varios, que las traducciones quizás no sean siempre exactas, se logra potenciar la atención lectora respecto de la problemática privilegiada. 
Cervantes Saavedra, Miguel de, Los trabajos de Persiles y Sigismunda, edición, prólogo y notas de Carlos Romero Muñoz, Madrid, Cátedra, 1997.

Forcione, Alban K., «Lope's broken clock: baroque time in The Dorotea», Hispanic Review, 37 (1969), pp. 459-490.

Gourgouris, Stathis, «The Late Style of Edward Said», Alif. Journal of Comparative Poetics, julio, 2005.

Grilli, Giuseppe, 'De senectute’. Cervantes último, Roma, Aracne Editrice, 2016.

Herráiz de Tresca, Teresa, «Humor y muerte en el prólogo del Persiles», Criticón, 44 (1988), pp. 55-59.

Lamanna, Natalia, «Los trabajos del decir: las voces del silencio», en Alicia Parodi (ed.), Para leer a Cervantes II. Las 'Ejemplares', el 'Persiles', Buenos Aires, Eudeba, 2007, pp. 133-158.

Mayans y Siscar, Gregorio, Vida de Miguel de Cervantes Saavedra, Madrid, EspasaCalpe, 1972.

Menéndez y Pelayo, Marcelino, Historia de los heterodoxos españoles, Alicante, edición digital de la Biblioteca Virtual Miguel de Cervantes. <http://www. cervantesvirtual.com/obra-visor/historia-de-los-heterodoxos-espanoles/html>.

Menéndez y Pelayo, Marcelino, «Cultura literaria de Miguel de Cervantes y elaboración del Quijote», en Obras completas de Menéndez y Pelayo, VI (Estudios y discursos de crítica histórica y literaria, I, Madrid, CSIC, 1941.

Molho, Maurice, «Para introducir Los trabajos de Persiles y Sigismunda», De Cervantes, Paris, Editions Hispaniques, 2005.

Oleza, Joan, «Las opciones dramáticas de la senectud de Lope» en José María DíezBorque y José Alcalá-Zamora (coord.), Proyección y significado del teatro clásico español. Homenaje a Alfredo Hermenegildo y Francisco Ruiz Ramón, Madrid, Sociedad Estatal para la Acción cultural exterior, 2004.

Oleza, Joan, «El Lope de los últimos años y la materia palatina», en Estaba el jardín en flor... Homenaje a Stefano Arata, Criticón, 87-88-89 (2003), pp. 603-620.

Ortiz Robles, Mario, «Late Style in Cervantes’s Los trabajos de Persiles y Sigismunda», E-Humanista/Cervantes, 5 (2016), pp. 413-425.

Pelorson, Jean-Marc, El desafio del 'Persiles', Toulouse, Presses Universitaires du Mirail, Anejos de Criticón, 16 (2003).

Redondo, Augustin, «El Persiles, "libro de entretenimiento" peregrino», en Alicia Villar Lecumberri (ed.), Peregrinamente peregrinos. Actas del V Congreso internacional de la Asociación de Cervantistas, Lisboa, Fundación Calouste Gulbenkian/Asociación de Cervantistas, 2004, pp. 67-102.

Rozas, Juan Manuel, «El ciclo de senectute: Lope y Felipe IV», en Estudios sobre Lope de Vega, Madrid, Cátedra, 1990, pp. 73-131. 
Said, Edward, «Lo pertinente y lo tardío», en Sobre el estilo tardio. Música y literatura a contracorriente, Buenos Aires, Debate, 2009.

Vélez-Sainz, Julio, El Parnaso español. Canon, mecenazgo y propaganda en la poesía del Siglo de Oro, Madrid, Visor Libros, 2006.

Vélez-Sainz, Julio, «"Musa iocosa mea": Entusiasmo, auto-representación y muerte en el 'Prólogo' al Persiles», Studia Aurea, 10 (2016), pp. 221-237.

Wood, Michael, «Introducción», en Edward Said, Sobre el estilo tardío. Música y literatura a contracorriente, Buenos Aires, Debate, 2009, pp. 13-14.

Wright, Elizabeth R., Pilgrimage to Patronage: Lope de Vega and the Court of Philip III, 1598-1621, Lewisburg, Bucknell University Press, 2001.

Zerari-Penin, María, «Fleurs de cimetière. Réflexions sur l'oeuvre ultime, le 'style de viellesse' et le 'style tardif'», E-Spania, 18, Juin (2014). <http://journals. openedition.org/e-spania/23492>; <https://doi.org/10.4000/e-spania.23492> [consultado 9.10.2018]. 